\title{
Evolution of the levels of human leukocyte antigen G (HLA-G) in Beninese infant during the first year of life in a malaria endemic area: using latent class analysis
}

Tania C. d'Almeida ${ }^{1,2^{*}}$, Ibrahim Sadissou ${ }^{2,3,4,5}$, Gilles Cottrell ${ }^{2,3}$, Rachida Tahar ${ }^{2,3}$, Philippe Moreau6, Benoit Favier ${ }^{6}$, Kabirou Moutairou ${ }^{5}$, Eduardo A. Donadi ${ }^{7}$, Achille Massougbodji ${ }^{4,5}$, Nathalie Rouass-Freiss ${ }^{6}$, David Courtin ${ }^{2,3}$ and André Garcia ${ }^{2,3}$

\begin{abstract}
Background: HLA-G, a non-classical HLA class I antigen, is of crucial interest during pregnancy by inhibiting maternal immune response. Its role during infections is discussed, and it has been described that high levels of soluble HLA-G during childhood increase the risk of malaria. To explore more precisely interactions between soluble HLA-G and malaria, latent class analysis was used to test whether distinct sub-populations of children, each with distinctive soluble HLA-G evolutions may suggest the existence of groups presenting variable malaria susceptibility.

Method: A study was conducted in Benin from 2010 to 2013 and 165 children were followed from birth to 12 months. Evolution of soluble HLA-G was studied by the latent class method.

Results: Three groups of children were identified: one with consistently low levels of soluble HLA-G during follow-up, a second with very high levels and a last intermediate group. In all groups, low birth weight, high number of malaria infections and high exposure to malaria transmission were associated with high level of soluble HLA-G. Placental malaria was not. Presence of soluble HLA-G in cord blood increased the probability of belonging to the highest trajectory.

Conclusion: These results, together with previous ones, confirm the important role of HLA-G in the individual susceptibility to malaria. Assaying soluble HLA-G at birth could be a good indicator of newborns more fragile and at risk of infections during childhood.
\end{abstract}

Keywords: sHLA-G, Evolution, Groups, Infancy, Malaria, Benin

\section{Background}

Human Leukocyte Antigen-G (HLA-G) is a non-classical HLA class Ib antigen, with important immuneregulatory functions [1], that differs from classical HLA class I antigens by a low amount of polymorphism and a tissue restricted expression [2, 3]. The physiological HLA-G expression is restricted to fetal tissues such

\footnotetext{
*Correspondence: carennedalmeida@gmail.com

2 UMR216 MERIT"Mère et enfant face aux infections tropicales", Institut de

Recherche pour le Développement, Paris, France

Full list of author information is available at the end of the article
}

as invasive cytotrophoblast and amnion, and in adults, to immune-privileged organs, cornea, thymus, pancreatic islets, endothelial cell precursors, and erythroblasts. Dendritic cells and macrophages can also express HLA-G [4]. Seven alternative proteins can be generated, four membrane-bound and three secreted isoforms [3-5]. HLA-G is primarily expressed during pregnancy and plays an important role in maternal tolerance of the fetus. Trophoblast cells are protected by HLA-G which inhibit the cytolytic activity of NK cells and protect the semiallogenic fetus from maternal rejections responses $[4,6,7]$. 
Apart from pregnancy, HLA-G has been shown to be expressed in many types of tumours [8-11]. Tumour cells express HLA-G to escape to immunity and high levels of soluble HLA-G (sHLA-G) have been related with unfavourable outcome of prognosis [12, 13]. In transplantation, HLA-G molecule has been shown to be important for a better allograft acceptance, whereas low serum levels seem to increase the risk of autoimmunity $[13,14]$ and allergy [15]. If the role of HLA-G with viral infections is admitted [15-18], this association with parasite infections is much less documented $[19,20]$. Recently, it was reported that genetic polymorphisms in $H L A-G 3^{\prime} \mathrm{UTR}$ were associated with susceptibility to human African trypanosomiasis and could influence the clinical and immunological responses directed to Plasmodium falciparum [21-23].

A recent work reported that high levels of sHLA-G were significantly associated with a higher incidence ratio of malaria in Beninese children [24] consistent with the fact that the inhibition of immune responses by HLA-G expression could lead to a greater susceptibility to malaria. In this previous analysis, hierarchical mixed models have been used to deal with the repeated measures design. However, mixed models make the assumption that individuals are randomly drawn from a homogeneous population. As a complement it seemed interesting to test whether distinct subpopulations of children are present in the overall population, each with its own parameters, with distinctive sHLA-G evolutions, or trajectories. The identification of trajectories of sHLA$G$ through the first year of life and risk factors that predispose to, or modify, a particular trajectory may suggest the existence of individual with variable malaria susceptibility. Latent class analysis (LCA) approach is ideally suited to explore this issue $[25,26]$.

Thus, the main objective of the present work was to explore the existence and characteristics of groups of children with different patterns of soluble HLA-G evolution between birth and 12 months of life in a cohort of Beninese children exposed to malaria, using latent class analysis.

\section{Methods}

\section{Study design}

The work is part of a research programme conducted in southern Benin. The protocol has been widely described elsewhere [24, 27] and will be presented below briefly.

\section{Site description}

The study included nine villages and three health centres: Tori Avamè, Tori Cada and Tori Gare, providing primary healthcare, and holding a maternity for antenatal care and childbirth. The study site was located in a malaria endemic area with an incidence rate of $16.9 \%$ in 2013 [28]. Malaria is transmitted mainly by Anopheles gambiae s.s. and Anopheles funestus [29]. P. falciparum is the most prevalent parasite and infectious peaks occur during the rainy season [28].

\section{Study population}

More than 600 pregnant women were included at delivery from June 2007 to July 2008; they did reside in the villages of the study and give birth in one of the three health centres. Twins, stillbirths and HIV-positive women were excluded. Newborns included were followed-up from birth to 12 months. Among them, 165 mother/infant pairs were selected based on the "placental infection" status of the mother at delivery. Placental infection was defined by the presence of asexual forms of $P$. falciparum in placental blood smears. Population was composed by the totality of mother/infant pairs with placental infection $(\mathrm{n}=51$ ) and 114 randomly selected newborns whose mothers were not infected.

\section{Data collection}

Maternal characteristics and data on the course of the current pregnancy were documented through a questionnaire. At delivery, peripheral blood was sampled for soluble HLA-G and haemoglobin measurements. Thick and thin placental smears were performed to determine the existence of a placental P. falciparum infection. Cord blood was collected for soluble HLA-G measurements.

At birth, gestational age was estimated using Ballard method [30] and newborn were weighed. Monthly, thick blood smear (TBS) was systematically made (in absence of fever or other clinical sign) to detect asymptomatic malaria infection. Weekly, axillary temperature was measured by trained community health worker. In case of temperature higher than $37.5^{\circ} \mathrm{C}$, the child was lead to the health centre. A questionnaire was filled out and a TBS and a rapid diagnosis test (RDT) were made. Symptomatic malaria cases were defined as fever $\left(>37.5{ }^{\circ} \mathrm{C}\right)$ with RDT and/or TBS positive. TBS obtained monthly or during consultations were stained with Giemsa. Leucocytes and parasites were counted simultaneously until leukocyte or parasite numbers reached 500. A TBS was declared negative if no parasite was found after counting 500 leucocytes. TBSs were read by two laboratory technicians with less than $1 \%$ disagreement. Malaria cases were treated with an artemisinin-based combination therapy (ACT), as recommended in Benin [31, 32]. In case of fever or any clinical sign, mothers were invited to bring their children to health centre where the same protocol was applied. At birth (in cord blood) and at 3, 6, 9 and 12 months old, venous blood was sampled to quantify the level of sHLA-G. Finally, a time-dependent 
environmental risk of exposure to malaria was assessed for each child by means of a statistical predictive model [33].

\section{Variable of interest: soluble HLA-G}

Assays of sHLA-G have been made by ELISA method. Quantification of sHLA-G correspond to the soluble isoform HLA-G5 and HLA-G1 (after cleavage from the membrane-bound form). Techniques used for these manipulations are extensively described in another study [24]. Soluble HLA-G levels were used as a quantitative variable (after logarithmic transformation) and as a dichotomic one (presence $v s$ absence).

\section{Covariates}

From mothers, the following variables were used: Age; parity (primipare vs. multipare); placental malaria; anemia ( $\mathrm{Hb}$ level before delivery $<11 \mathrm{~g} / \mathrm{dl}$ ) and sHLA-G in peripheral blood. From children: low birth weight (LBW) $(<2500 \mathrm{~g})$; preterm birth (gestational age $<37$ weeks of gestation); gender; number of malaria attacks during the follow-up (used as a quantitative variable, or binary variable with two groups: 0 or 1 vs. more than 1); environmental risk of malaria (quantitative time-dependent variable, used as quartiles); sHLA-G level in cord blood and parasite density (PD defined as the number of $P$. falciparum per 100 leucocytes).

\section{Statistical analysis}

Latent class analysis was used to identify the sHLA-G level trajectories and assess their association with the covariates.

A general model's formulation is:

$$
\begin{aligned}
y_{i t}= & \beta_{0}^{j}+\beta_{1}^{j} A g e_{i t}+\beta_{2}^{j} A g e_{i t}^{2}+\beta_{3}^{j} A g e_{i t}^{3}+\alpha_{1}^{j} X_{1 t} \\
& +\cdots+\alpha_{p}^{j} X_{p t}+\varepsilon_{i t}
\end{aligned}
$$

where $y_{i t}$ is the response variable (sHLA-G level of the ith children at age $\mathrm{t}$ ), the $\beta^{j}$ are the coefficients associated to the children's age in the jth group and the $\alpha^{j}$ are the coefficients associated to covariates in the jth group (the index $t$ specifies that the covariates can depend on time as the environmental risk of malaria) and $\varepsilon_{\mathrm{it}}$ the residual variation $\left[\varepsilon_{i t} \sim \mathrm{N}\left(0, \sigma^{2}\right)\right]$.

The posterior probability $\pi_{j}\left(z_{i}\right)$ that a child $\mathrm{i}$ with the covariates vector $z_{i}$ belongs to the group $\mathrm{j}$ is: $\pi_{j}\left(z_{i}\right)=\frac{\exp \left(z_{i} \theta_{j}\right)}{\sum_{j} \exp \left(z_{i} \theta_{j}\right)}$ with covariates vector $z_{i}$ and its corresponding coefficients vector $\theta_{j}$.

The analysis was performed using three steps.

Firstly, each sHLA-G trajectory has been modelled, by means of a polynomial function of time of degree 3 , without introducing any covariate. The most appropriate number of trajectories was selected using the Bayesian information criterion (BIC). The group prevalence, that should not be less than $5 \%$ of the total number of the sample, was used as additional criteria, for practical interpretation [34].

Secondly, the effect of the covariates on each trajectory was studied using univariate and multivariate analysis. Only covariates associated with $p<0.20$ during univariate analysis were entered in the multivariate step. Statistical significance in the final model was set at $p<0.05$. The effect of covariates on HLA-G trajectories can be identical for each trajectory or different according to them. During this step a particular attention was paid to the stability of the trajectories determined during the first step. Indeed, as mentioned by Nagin [35] the addition of significant covariates to the model should not widely modify the percentage of subjects in each trajectory.

In the final multivariate model each individual was assigned to the trajectory group for which he had the highest posterior probability. Within each group, posterior probability values greater than or equal to 0.7 indicate adequate internal reliability [36]. All these criteria allowed us to make a definitive choice of the appropriate number of classes.

Finally, in the third step, the predictor effect of some covariates to belong to one or more trajectory has been tested. This concerned placental malaria, parity, maternal anaemia, LBW and sHLA-G in cord blood.

All analyses were performed with the Stata ${ }^{\circledR}$ Software, Version 12 (StatCorp LP, College Station, TX, USA), using the syntax dedicated to generalized linear latent and mixed models (GLLAMM).

\section{Ethics}

The study's protocol was approved by the Ethics Committee of the "Faculté des Sciences de la Santé (FSS)" of Cotonou and the "Institut de Recherche pour le Développement (IRD)" Consultative Ethics Committee. All mothers and fathers were informed during antenatal care visits and meetings conducted in villages before the beginning of the study. Mothers signed informed consent written in French and explained in local language.

\section{Results}

At delivery sHLA-G was measured for all mothers and all cord blood samples $(n=165)$. During the follow-up, a total of 445 measurements were performed from 3 to 12 months distributed as follows: $109 / 165$ at 3 months, 113 at 6 months, 114 at 9 months and 109 at 12 months. Overall, a total of 775 measurements (mother, cord, 3, 6, 9 and 12 months) were performed. In most cases, an HLA-G measurement was missing because the mother had not attended a quarterly visit. Only 10 children $(6.1 \%)$ were present for a single visit. 


\section{Characteristics of the study population}

The mean age of the mothers was 26.75 years $(\mathrm{SD}=6.37$, range 16-49). Most women were multi-gravidae (81.2\%, $\mathrm{n}=134)$, and $40 \%$ were suffering from anaemia at delivery.

The mean birth weight of newborns was 2,964 grammes $(\mathrm{SD}=448.31)$ and $10.9 \%(\mathrm{n}=18 / 165)$ of children had a LBW. Eighty-eight children (53.33\%) were female and eighteen children were premature. During the follow-up, $50.9 \%(\mathrm{n}=84 / 165)$ of children had at least one malaria infection, and $10 \%$ more than two. The most infected child had seven infections.

\section{Soluble HLA-G at delivery}

At delivery, $78.2 \%$ of women had detectable levels of sHLA-G ( $n=129 / 165)$. The mean level in the peripheral blood for all women was $19.12 \mathrm{ng} / \mathrm{ml}(\mathrm{SD}=25.60$, range $0-132.22)$. Sixty percent of children $(n=99 / 165)$ had detectable sHLA-G in cord blood and the mean level was $16.22 \mathrm{ng} / \mathrm{ml}(\mathrm{SD}=26.83$, range $0-128.52)$. A strong correlation has been described previously between the mother/newborn (cord blood) sHLA-G levels, with a significantly higher level in mother's blood at delivery [24]. The sHLA-G level increased gradually before stabilizing after 9 months (Fig. 1).

\section{Trajectory groups of HLA-G}

During the first step of analysis, groups of children following the same pattern of sHLA-G have been identified. Using the BIC as criteria, the two-group model showed a higher BIC than both three- and four-group models. The four-group model was selected when compared to the three groups (Table 1). In the three-group model, $16.9 \%$ of the children have high levels of sHLA-G and $53.8 \%$ remained at low levels whereas the third trajectory

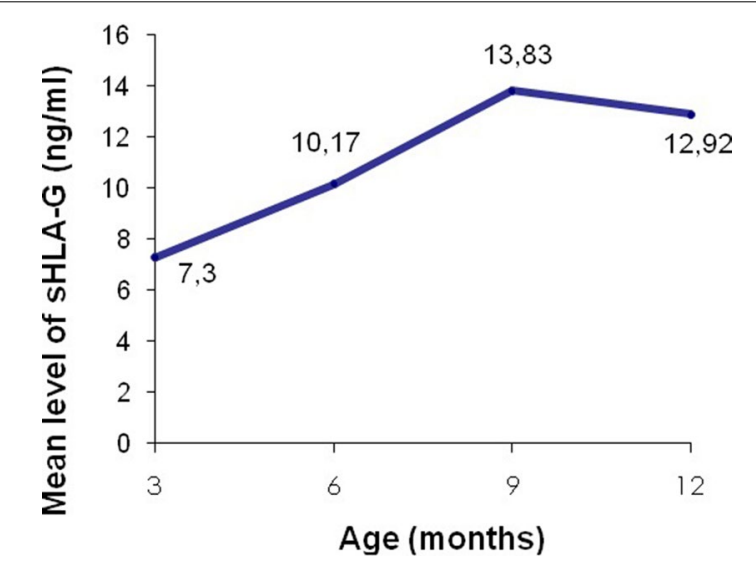

Fig. 1 Evolution of the mean level of sHLA-G in newborns in the first year of life
(29.3\%) was characterized by low levels tending to rise after 6 months. When a fourth trajectory was added, a new intermediate one appeared starting with very low levels until 6 month of age and rapidly rising (Fig. 2; Table 1). From three-group model the following pattern was constantly identified: one trajectory with low levels of sHLA-G (the higher percentage), one with high levels (the lower percentage) and an intermediate one. Adding a new trajectory led to the same trend with the emergence of new intermediate group, representing low percentages of the population. To pursue analysis, the three- and the four-trajectory models only were used (Table 1).

\section{Effect of covariates on the trajectories}

Using the three-group model, placental malaria $(\mathrm{p}=0.59)$, parity $(\mathrm{p}=0.31)$, gender $(\mathrm{p}=0.95)$, prematurity $(\mathrm{p}=0.43)$, maternal anaemia $(\mathrm{p}=0.51)$ and parasite density $(p=0.52)$ have no significant effect on the dynamics of sHLA-G. In contrast, LBW appeared to be significantly associated with higher levels of sHLAG $\left(\mathrm{p}<10^{-3}\right)$. Similarly, detectable sHLA-G level in cord blood, or in mother's peripheral blood at delivery, was associated with higher levels of sHLA-G from 3 to 12 months of life ( $\mathrm{p}<10^{-3}$ in the both case). Having more than one malaria attack during the follow-up was significantly associated with higher levels of sHLA-G $(p=0.008)$. In the same way, the higher levels of malaria exposure were significantly related to the high levels of sHLA-G ( $\mathrm{p}=0.01)$.

During multivariate analysis "placental malaria" was forced in the model. The results are presented in Table 2. LBW, presence of sHLA-G in cord blood or in maternal blood at delivery were significantly associated with higher levels of sHLA-G $\left(\mathrm{p}<10^{-3}\right)$. High exposure to malaria and having more than one malaria infection during the follow-up were significantly associated with high levels of sHLA-G ( $\mathrm{p}=0.001$ and $\mathrm{p}=0.002$, respectively). In the final model, the proportions of the groups were $50.9,27.2$ and $21.9 \%$, respectively for the low, intermediate and high trajectories (Table 1). All these covariates have similar effects within each trajectory. As an example, children born with a LBW have significantly higher sHLA-G levels during their first year of live whatever the group they belong (Fig. 3).

Using the four-trajectory model, the same pattern of results was obtained. However, the introduction of LBW resulted in an increase of the proportion of children belonging to the high trajectory from 8 to $17 \%$, while the intermediate-high trajectory decreased from 22 to $15 \%$, consistent with a low stability of the four-trajectory model (Table 1).

In the third step of analysis, the role of placental malaria, parity, maternal anaemia, presence of sHLA-G 
Table 1 Distribution of newborns in the two-, three- and four-group models

\begin{tabular}{|c|c|c|c|c|c|c|}
\hline \multirow[t]{2}{*}{ Trajectories } & \multirow[t]{2}{*}{ Model } & \multirow[t]{2}{*}{$\mathrm{BIC}^{\mathrm{a}}$} & \multicolumn{4}{|c|}{ Distribution of newborns in groups } \\
\hline & & & High (\%) & Intern & & Low (\%) \\
\hline \multirow[t]{2}{*}{2} & Empty $^{\mathrm{b}}$ & 1494,644 & 27.2 & 72.78 & & \\
\hline & Full ${ }^{\mathrm{C}}$ & & 24.2 & 75.8 & & \\
\hline \multirow[t]{2}{*}{3} & Empty & 1464,333 & 16.9 & 29.3 & 53.8 & \\
\hline & Full & & 21.9 & 27.2 & 50.9 & \\
\hline \multirow[t]{2}{*}{4} & Empty & 1438,894 & 7.7 & 21.9 & 19.9 & 50.5 \\
\hline & Full & & 13.9 & 15.7 & 23.1 & 47.3 \\
\hline
\end{tabular}

a A lower BIC indicates a better fitting

b With no covariate

c With all significant covariates in multivariate analysis
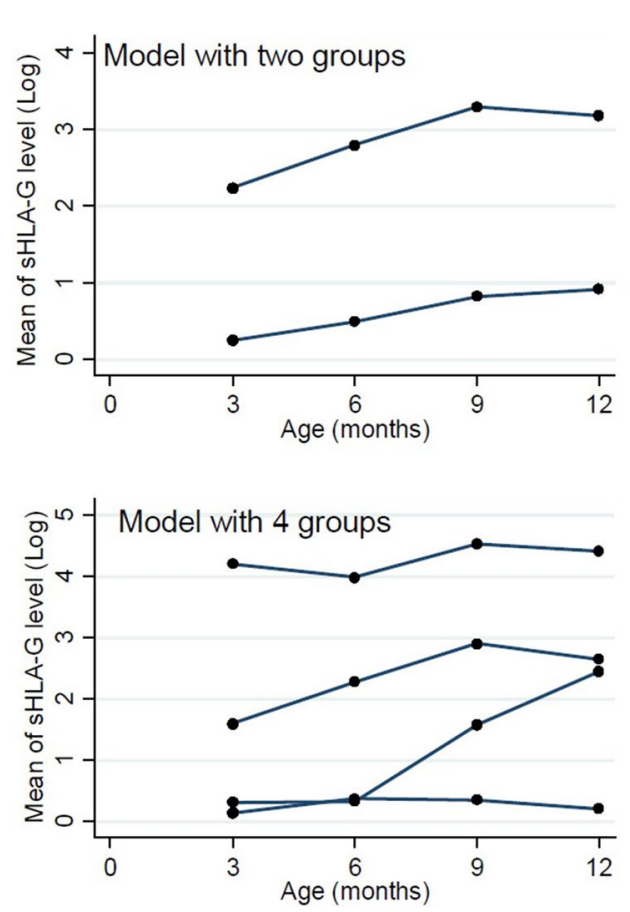

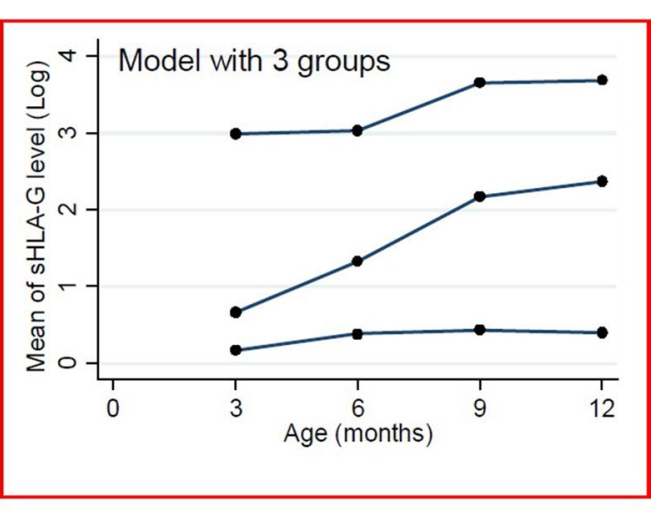

Fig. 2 Trajectories of soluble HLA-G for the two-, three- and four-group models

in cord blood and LBW as predictor to belong to either group, were examined. Among them, for the three-group model only the presence of SHLA-G in cord blood was associated with a significantly higher probability to belong to the high or intermediate trajectory $(\mathrm{OR}=22.8$ and $\mathrm{OR}=6.1$, respectively). Accordingly, a child born with sHLA-G in cord blood would have a probability of $76.25,20.40$ and $3.35 \%$ to belong to the high, intermediate or the low trajectory, respectively.

When the same analysis was performed using the fourgroup model, convergence was not achieved, reinforcing the instability of this model. Taken together, the results are consistent with the existence of three-trajectory model. With this model $97 \%$ of children from the low trajectory, 91.7 and $83 \%$ of children from respectively the intermediate and high trajectories were classified as belonging to these groups with a posterior probability greater than $70 \%$.

Table 3 shows the characteristics of the children and of their mothers in the three groups. LBW children seemed to be more present in the "high trajectory" than in others. Children in this group were born to mothers with detectable sHLA-G at delivery, and the majority had SHLA-G in cord blood. 
Table 2 Risk factors of soluble HLA-G evolution from 3 to 12 months in 165 newborns at Tori Bossito, 2007-2010: latent class analysis

\begin{tabular}{|c|c|c|c|c|}
\hline Covariates & Univariate estimation $^{a}$ & Adjusted estimation $^{\mathbf{b}}$ & $95 \% \mathrm{Cl}$ & $\mathrm{p}$ value \\
\hline Intercept & - & 0.58 & $0.28-0.88$ & $<10^{-3 *}$ \\
\hline \multicolumn{5}{|l|}{ HLA-G in cord blood } \\
\hline No & - & - & & \\
\hline Yes & 0.60 & 0.42 & $0.15-0.70$ & $0.002^{\mathrm{C*}}$ \\
\hline \multicolumn{5}{|c|}{ Low birthweight (<2500 g) } \\
\hline No & - & - & & \\
\hline Yes & 0.62 & 0.86 & $0.42-1.29$ & $<10^{-3 *}$ \\
\hline \multicolumn{5}{|l|}{ Malaria infections } \\
\hline$\leq 1$ & - & - & & \\
\hline$>1$ & 0.20 & 0.33 & $0.11-0.54$ & $0.003^{*}$ \\
\hline \multicolumn{5}{|c|}{ Malaria exposure (quartiles) } \\
\hline Low & - & - & & \\
\hline Middle & 0.33 & 0.43 & $0.19-0.68$ & $0.001^{*}$ \\
\hline High and very high & 0.32 & 0.35 & $0.13-0.56$ & $0.002^{*}$ \\
\hline \multicolumn{5}{|l|}{ Placental malaria } \\
\hline No & - & - & & \\
\hline Yes & -0.07 & -0.12 & $-0.35-0.11$ & 0.36 \\
\hline
\end{tabular}

${ }^{a}$ Univariate estimation represents the coefficient of the univariate regression

${ }^{\mathrm{b}}$ Adjusted estimation is obtained after the multivariate analysis

c Results were the same, when "HLA-G in cord blood" was replaced by "HLA-G in maternal peripheral blood". Presence of sHLA-G in maternal blood is highly significantly related to high level of HLA-G in newborns during the first 12 months. We did not introduce together the two covariates in the model because they are highly correlated [24]

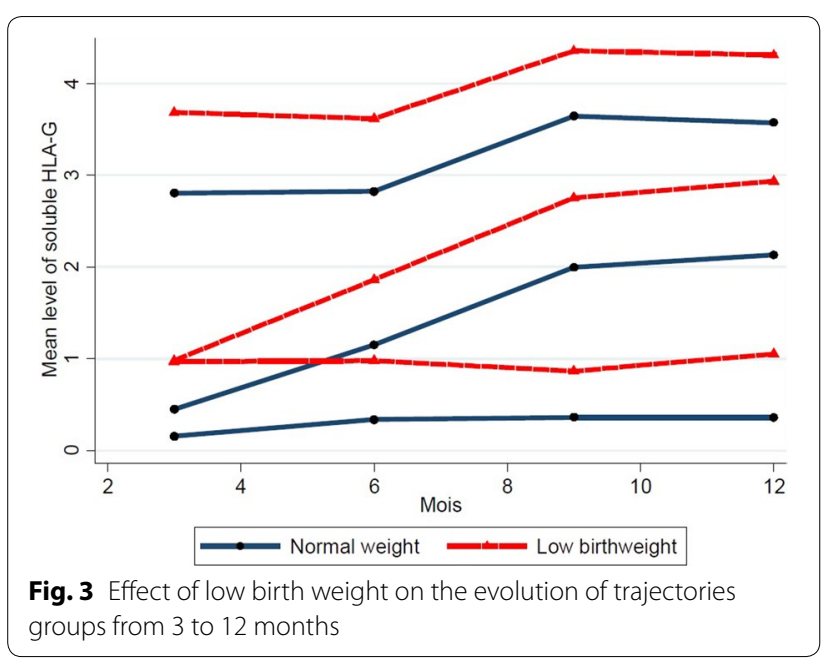

\section{Discussion}

The present work is complementary to study of Sadissou et al., describing the evolution of sHLA-G in a population of African infants [24]. In the first study, a strong correlation has been shown between mother and cord blood levels of sHLA-G at delivery, as well as an association between LBW and high level of sHLA-G during the first year of life. In addition, high levels of sHLA-G were associated with an increase of the incidence ratio of malaria during the follow-up, but the total number of malaria infections during the follow-up was not associated with the level of sHLA-G.

The present analysis, confirms these results, and provides new understanding by identifying new determinants of sHLA-G evolution. Indeed, although in the first study, the level of sHLA-G increased the risk of infection in the following quarter, any association has not been highlighted between the level of sHLA-G and the overall number of malaria infections during the follow-up. In this complementary analysis, this association is strongly significant. The difference between these two results could be due to the complexity of the effect of malaria infection that cannot be pointed out under the hypothesis that all children belong to the same homogeneous population. Using latent class approach allows hypothesizing that distinct subpopulations of children are presents in the overall population, each with its own characteristics, with distinctive sHLA-G evolutions. This approach permitted us to explore more precisely the complex association between malaria and HLA-G.

The mechanisms by which $H L A-G$ gene expression is regulated are only partially understood [37]. Concerning infections, HIV or hepatitis, infected patients have higher level of sHLA-G, and it has been suggested that 
Table 3 Distribution of 165 mother/child pairs in the different groups, 2007-2010

\begin{tabular}{|c|c|c|c|}
\hline Covariates & $\begin{array}{l}\text { High trajectory } \\
(n=28 / 165)\end{array}$ & $\begin{array}{l}\text { Intermediate trajectory } \\
(n=46 / 165)\end{array}$ & $\begin{array}{l}\text { Low trajectory } \\
(n=91 / 165)\end{array}$ \\
\hline \multicolumn{4}{|l|}{ Newborns (165) } \\
\hline \multicolumn{4}{|l|}{ Level of sHLA-G } \\
\hline 3 months & 3.29 & 0.58 & 0.14 \\
\hline 6 months & 3.21 & 1.35 & 0.31 \\
\hline 9 months & 3.78 & 2.32 & 0.33 \\
\hline 12 months & 3.88 & 2.47 & 0.30 \\
\hline \multicolumn{4}{|l|}{ Gender } \\
\hline Female & $17(60.71 \%)$ & $24(52.17 \%)$ & $47(51.65 \%)$ \\
\hline Male & $11(39.28 \%)$ & $22(47.83 \%)$ & $44(48.35 \%)$ \\
\hline Birth weight & $\begin{array}{l}2894.52 \\
(S D=369.30)\end{array}$ & $\begin{array}{l}3076.63 \\
(S D=500.10)\end{array}$ & $\begin{array}{l}2928.57 \\
(S D=437.05)\end{array}$ \\
\hline Low birth weight & $17.86 \%(n=5)$ & $13.04 \%(n=6)$ & $7.69 \%(n=7)$ \\
\hline Preterm & $10.71 \%(n=3)$ & $6.52 \%(n=3)$ & $13.19 \%(n=12)$ \\
\hline Detectable sHLA-G in cord blood & $96.43 \%(n=27)$ & $73.91 \%(n=34)$ & $41.76 \%(n=38)$ \\
\hline Number of malaria infections during the follow-up & $\begin{array}{l}1.11 \\
(S D=1.31)\end{array}$ & $\begin{array}{l}0.96 \\
(S D=1.46)\end{array}$ & $1.13(\mathrm{SD}=1.41)$ \\
\hline \multicolumn{4}{|l|}{ Mothers (165) } \\
\hline Age (years) & $26.54(\mathrm{SD}=6.08)$ & $28.15(\mathrm{SD}=6.06)$ & $25.78(S D=6.48)$ \\
\hline Parity & $25.00 \%(7)$ & $13.04 \%(6)$ & $19.78 \%(18)$ \\
\hline Placental malaria & $21.43 \%(6)$ & $26.09 \%(12)$ & $36.26 \%(33)$ \\
\hline Detectable sHLA-G in peripheral maternal blood & $100.00 \%(28)$ & $93.48 \%(43)$ & $63.74 \%(58)$ \\
\hline
\end{tabular}

these levels induce tolerance and contribute to immune evasion of virus [38-42]. Although, to date, such hypothesis has not been clarified for malaria; it could be hypothesized that the same phenomenon occurs during malaria infection leading to immune evasion. Indeed, P. falciparum could upregulate the HLA-G secretion through the stimulation of cytokines such as IL-10 and IFN- $\gamma$. HLA-G is known to inhibit the function of T, NK and B cells through direct interaction with ILT2. Recently, Naji et al. showed that HLA-G inhibits B cell proliferation, differentiation, and immunoglobulin (Ig) secretion in both $\mathrm{T}$ cell-dependent and -independent models of B cell activation. HLA-G also acts as a negative $B$ cell regulator in modulating $B$ cell antibodies secretion in a xenograft mouse model [43]. Taken together all these arguments are consistent with the existence of a complex interaction between HLA-G, immunity and P. falciparum infection, leading to a lower B cell response. As IgG antibodies play a pivotal role in anti-malarial protection [44-46], the inhibition of IgG specifically directed against $P$. falciparum mediated by HLA-G, not only allows the parasite to escape the immune system but also is responsible of the higher susceptibility to infection showed previously.

However, other factors could influence HLA-G secretion during malaria infection. It has been shown that hypoxia could play a role in HLA-G regulation during pregnancy [47], in some cancer [48] but also in more physiologic but extreme life conditions like altitude [49]. Tissue hypoxia resulting from decreased microcirculatory flow due to parasite sequestration and endothelial dysfunction contributes to the pathogenesis of malaria in children $[50,51]$. The results could be consistent with the fact that malaria related hypoxia is already present very early in life and associated with an increase of SHLA-G levels, and consequently strengthening the inhibition of immunity.

More than $60 \%$ of the children born with a LBW belong to the high and intermediate trajectories. It is widely accepted that birth weight is a key indicator of fetal and neonatal health [52-54] and overall 60-80\% of infants who die during the neonatal period are children born with LBW [55]. The association between LBW and HLA-G has already been shown in this same cohort using mixed model [24]. However, the present approach allows pointing out a very interesting aspect, which has not been demonstrated by previous analysis. Indeed, children born with detectable HLA-G in their cord blood have a greater probability to belong to the higher or intermediate trajectories than other children, and hence be concerned by LBW. Considering the frailty of LBW children, the detection of such high-risk individuals could have huge public health consequences. Taking into account the strong correlation between SHLA-G in cord blood and in mother's blood at delivery, the mother's 
sHLA-G level could be considered as a potential marker of high-risk newborn. Soluble HLA-G has already been proposed as predictor of in vitro fecundation outcome [56], but also as biomarker of allergy [57], allograft and cancers $[58,59]$. A follow-up of pregnant women and of their offspring over 2 years is now ongoing in Benin to test whether the sHLA-G level early in pregnancy is also correlated with HLA-G level in cord blood or with infectious morbidity during the first 2 years of life.

Latent class analysis approach is more and more frequently used in biomedical research [60]. It is an extension of mixed models that assume the presence of several groups of subjects (latent groups) sharing a particular evolution trajectory of some attribute. This approach allows a better understanding of the phenomenon under study and the formulation of new questions or hypotheses $[61,62]$. This methodology is part of mixture modelling, a wide data analysis approach allowing studying unobserved heterogeneity in a population [60]. The question of the number of trajectories remains of great importance and to date, there is no single statistical test to determine the correct number of latent classes [63]. The selection of the best model needs to take into account statistical measures of model fitting but also the interpretation of the output, in particular the relevance of the different groups, based on the literature or the expert's knowledge. BIC was used as statistical criteria although others can be proposed. Bootstrap Likelihood Ratio test (BLRT) has been proposed as being more powerful. However, BLRT needs an increased computation time and finally the authors recommended using BIC as the first step [64]. In the data, using BIC would lead to choose a model with four trajectories instead of three. Both model have the same interpretation since the two intermediate trajectories in the four-group model share the same evolution, i.e. high level trajectory, low level trajectory and intermediate group(s) starting with low levels of sHLA-G and then growing up. However, models with more than three trajectories seem to present a lower stability. Finally, to deal with the possibility and complexity of these population mixture models, it could be of interest to pursue this exploration by using different methods in different populations.

A genetic association between $H L A-G$ and malaria has already been pointed out. Indeed, it has been shown that some polymorphisms of the HLA-G 3'UTR were associated with variable risk of infection [22], but also with antibody responses against $P$. falciparum. These associations have been identified in another population from Senegal. It has also been demonstrated that a strong molecular signature of balancing selection at $H L A-G$ 5 'URR exist and that this region may certainly be the direct target of selection [65]. These results strengthen the interest of this gene and of sHLA-G as potentially involved in differential susceptibility to malaria.

\section{Conclusion}

Summary, this study allowed a better understanding of the complex interaction between HLA-G and malaria infection and pointed out the potential interest of sHLA$G$ as marker of frailty.

\section{Abbreviations}

HLA-G: human leukocyte antigen-G; sHLA-G: soluble human leukocyte antigen-G; LCA: latent class analysis; TBS: thick blood smear; RDT: rapid diagnosis test; ACT: artemisinin-based combination therapy; LBW: low birth weight; PD: parasite density; BIC: Bayesian information criterion; GLLAMM: generalized linear latent and mixed models; SD: standard deviation; OR: odd ratio; NK: natural killer.

\section{Authors' contributions}

All the authors read and approved the final version of the manuscript. NR, BF, $D C$ and $A G$ have designed the study and wrote the protocol. IS has performed the immunoassays of HLA-G in collaboration with DC, BF, NR. TCA carried out the statistical analysis and drafted the manuscript. GC participated in the design of the study and the statistical analysis. AG conceived of the study, and participated in its design and coordination and helped to draft the manuscript. All authors read and approved the final manuscript.

\section{Author details}

${ }^{1}$ Université Pierre et Marie Curie, Paris, France. ${ }^{2}$ UMR216 MERIT"Mère et enfant face aux infections tropicales", Institut de Recherche pour le Développement, Paris, France. ${ }^{3}$ Université Paris Descartes, Paris, France. ${ }^{4}$ Centre d'Etude et de Recherche sur le Paludisme Associé à la Grossesse et à l'Enfance (CERPAGE), Cotonou, Benin. ${ }^{5}$ Université d'Abomey-Calavi, Cotonou, Benin. ${ }^{6}$ UMR Commissariat à l'Energie Atomique et aux Energies Alternatives (CEA), Université Paris Diderot - Paris 7, IMETI Service de Recherches en Hémato-Immunologie, Paris, France. ${ }^{7}$ Division of Clinical Immunology, School of Medicine of Ribeirão Preto, University of São Paulo, São Paulo, Brazil.

\section{Acknowledgements}

We are grateful to all the women and infants of Tori Bossito who agreed to participate to this project, the midwives, nurses, and health helpers of maternity health centres, the "Faculté des Sciences de la Santé" (FSS), the "Institut des Sciences Biomédicales Appliquées de Cotonou" (ISBA), and the "Programme National de Lutte contre le Paludisme" (PNLP) for their institutional support. We gratefully thank our field and laboratory teams.

\section{Competing interests}

The authors declare that they have no competing interests.

\section{Funding}

This work was financially and materially supported by the "Agence Nationale de la Recherche" (SEST (Santé Environnement Santé Travail) project 2006/040/001), the "Ministère des Affaires Etrangères" (REFS project 2006-22); the "Institut de Recherche pour le Développement" and the "Fondation pour la Recherche Médicale" (Grant FDM20130727043 to TC A.). The funders played no role in the study design, the data collection and analysis, the decision to publish, or the preparation of the manuscript.

Received: 6 June 2015 Accepted: 27 January 2016

Published online: 09 February 2016

\section{References}

1. Larsen MH, Bzorek M, Pass MB, Larsen LG, Nielsen MW, Svendsen SG, et al. Human leukocyte antigen- $G$ in the male reproductive system and in seminal plasma. Mol Hum Reprod. 2011;17:727-38. 
2. Carosella ED, Rouas-Freiss N, Paul P, Dausset J. HLA-G: a tolerance molecule from the major histocompatibility complex. Immunol Today. 1999;20:60-2

3. Carosella ED. The tolerogenic molecule HLA-G. Immunol Lett. 2011;138:22-4.

4. Curigliano G, Criscitiello C, Gelao L, Goldhirsch A. Molecular pathways: human leukocyte antigen G (HLA-G). Clin Cancer Res. 2013;19:5564-71.

5. Carosella ED, Rouas-Freiss N, Paul P, Dausset J. HLA-G: a tolerance molecule from the major histocompatibility complex. Immunol Today. 1999;20:60-2.

6. Rouas-Freiss N, Goncalves RM, Menier C, Dausset J, Carosella ED Direct evidence to support the role of HLA-G in protecting the fetus from maternal uterine natural killer cytolysis. Proc Natl Acad Sci USA. 1997;94:11520-5.

7. Moreau P, Paul P, Rouas-Freiss N, Kirszenbaum M, Dausset J, Carosella ED. Molecular and immunologic aspects of the nonclassical HLA class I antigen HLA-G: evidence for an important role in the maternal tolerance of the fetal allograft. Am J Reprod Immunol. 1998;40:136-44.

8. Cai MB, Han HQ, Bei JX, Liu CC, Lei JJ, Cui Q, et al. Expression of human leukocyte antigen $\mathrm{G}$ is associated with prognosis in nasopharyngeal carcinoma. Int J Biol Sci. 2012;8:891-900.

9. Jeong S, Park S, Park BW, Park Y, Kwon OJ, Kim HS. Human leukocyte antigen-G (HLA-G) polymorphism and expression in breast cancer patients. PLoS One. 2014. doi:10.1371/journal.pone.0098284.

10. Sheu JJC, Shih LM. Clinical and biological significance of HLA-G expression in ovarian cancer. Semin Cancer Biol. 2007;17:436-43.

11. Zheng J, Xu C, Chu D, Zhang X, Li J, Ji G, et al. Human leukocyte antigen G is associated with esophageal squamous cell carcinoma progression and poor prognosis. Immunol Lett. 2014;161:13-9.

12. Rouas-Freiss N, Moreau P, LeMaoult J, Carosella ED. The dual role of HLA-G in cancer. J Immunol Res. 2014;2014:359748. doi:10.1155/2014/359748.

13. Loustau M, Wiendl H, Ferrone S, Carosella ED. HLA-G 2012 conference: the 15-year milestone update. Tissue Antigens. 2013;81:127-36.

14. Waschbisch A, Sandbrink R, Hartung HP, Kappos L, Schwab S, Pohl C, et al. Evaluation of soluble HLA-G as a biomarker for multiple sclerosis. Neurology. 2011;77:596-8.

15. Ciprandi G, Deamici M. Soluble HLA-G serum levels depend on allergy type and IgE levels. Allergy Rhinol (Providence). 2014;5:9-11.

16. Amiot L, Vu N, Samson M. Immunomodulatory properties of HLA-G in infectious diseases. J Immunol Res. 2014;2014:298569. doi:10.1155/2014/298569.

17. Morandi F, Rouas-Freiss N, Pistoia V. The emerging role of soluble HLA-G in the control of chemotaxis. Cytokine Growth Factor Res. 2014;25:327-35.

18. LeBouder F, Khoufache K, Menier C, Mandouri Y, Keffous M, Lejal N, et al. Immunosuppressive HLA-G molecule is upregulated in alveolar epithelial cells after influenza A virus infection. Hum Immunol. 2009;70:1016-9.

19. Donaghy L, Gros F, Amiot L, Mary C, Maillard A, Guiguen C, et al. Elevated levels of soluble non-classical major histocompatibility class I molecule human leucocyte antigen (HLA)-G in the blood of HIV-infected patients with or without visceral leishmaniasis. Clin Exp Immunol. 2007; 147:236-40.

20. Robert-Gangneux F, Gangneux JP, Vu N, Jaillard S, Guiguen C, Amiot L. High level of soluble HLA-G in amniotic fluid is correlated with congenital transmission of Toxoplasma gondii. Clin Immunol. 2011;138:129-34.

21. Courtin D, Milet J, Sabbagh A, Massaro JD, Castelli EC, Jamonneau V, et al. HLA-G 3'UTR-2 haplotype is associated with Human African trypanosomiasis susceptibility. Infect Genet Evol. 2013;17:1-7.

22. Garcia A, Milet J, Courtin D, Sabbagh A, Massaro JD, Castelli EC, et al. Association of HLA-G 3'UTR polymorphisms with response to malaria infection: a first insight. Infect Genet Evol. 2013;16:263-9.

23. Sabbagh A, Courtin D, Milet J, Massaro JD, Castelli EC, Migot-Nabias F, et al. Association of HLA-G $3^{\prime}$ untranslated region polymorphisms with antibody response against Plasmodium falciparum antigens: preliminary results. Tissue Antigens. 2013;82:53-8.

24. Sadissou I, d'Almeida T, Cottrell G, Luty A, Krawice-Radanne I, Massougbodji A, et al. High plasma levels of HLA-G are associated with low birth weight and with an increased risk of malaria in infancy. Malar J. 2014;13:312. doi:10.1186/1475-2875-13-312.

25. Hagenaars JA, McCutcheon AL. Applied latent class analysis. Cambridge: Cambridge University Press; 2002.
26. McCutcheon AL. Latent class analysis. University paper series on Quantitatives Applications in the Social Sciences. Series no 07-064. Beverly Hills: Sage Publications; 1987.

27. Le Port A, Cottrell G, Martin-Prevel Y, Migot-Nabias F, Cot M, Garcia A. First malaria infections in a cohort of infants in Benin: biological, environmental and genetic determinants. Description of the study site, population methods and preliminary results. BMJ Open. 2012;2:000342. doi:10.1136/ bmjopen-2011-000342.

28. Hunt JS, Jadhav L, Chu WJ, Geraghty DE, Ober C. Soluble HLA-G circulates in maternal blood during pregnancy. Am J Obstet Gynecol. 2000;183:682-8.

29. Moiroux N, Djenontin A, Bio-Bangana AS, Chandre F, Corbel V, Guis H. Spatio-temporal analysis of abundances of three malaria vector species in southern Benin using zero-truncated models. Parasit Vectors. 2014;7:103. doi:10.1186/1756-3305-7-103.

30. Ballard JL, Khoury JC, Wedig K, Wang L, Eilers-Walsman BL, Lipp R. New Ballard Score, expanded to include extremely premature infants. J Pediatr. 1991;119:417-23.

31. Thibodeau V, Lajoie J, Labbe AC, Zannou MD, Fowke KR, Alary M, et al. High level of soluble HLA-G in the female genital tract of Beninese commercial sex workers is associated with HIV-1 infection. PLoS One. 2011;6:e25185. doi:10.1371/journal.pone.0025185.

32. Plan de suivi-évaluation 2011-2015 du programme national de lutte contre le paludisme. Bénin, Mai 2012.

33. Cottrell G, Kouwaye B, Pierrat C, le Port A, Bouraima A, Fonton N, et al. Modeling the influence of local environmental factors on malaria transmission in Benin and its implications for cohort study. PLoS One. 2012;7:e28812.

34. Andruff H, Carraro N, Thompson A, Gaudreau P, Louvet B. Latent class growth modelling: a tutorial. Tutor Quant Methods Psychol. 2009;5:11-24.

35. Nagin D. Group-based modeling of development. Cambridge: Harvard University Press; 2005

36. Andruff H, Carraro N, Thompson A, Gaudreau P, Louvet B. Latent class growth modelling: a tutorial. Tutor Quant Methods Psychol. 2009;5:11-24.

37. Moreau P, Flajollet $\mathrm{S}$, Carosella ED. Non-classical transcriptional regulation of HLA-G: an update. J Cell Mol Med. 2009;13:2973-89.

38. Donaghy L, Gros F, Amiot L, Mary C, Maillard A, Guiguen C, et al. Elevated levels of soluble non-classical major histocompatibility class I molecule human leucocyte antigen (HLA)-G in the blood of HIV-infected patients with or without visceral leishmaniasis. Clin Exp Immunol. 2007; 147:236-40.

39. Weng PJ, Fu YM, Ding SX, Xu DP, Lin AF, Yan WH. Elevation of plasma soluble human leukocyte antigen- $G$ in patients with chronic hepatitis $C$ virus infection. Hum Immunol. 2011;72:406-11.

40. Murdaca G, Contini P, Setti M, Cagnati P, Lantieri F, Indiveri F, et al. Behavior of non-classical soluble HLA class $G$ antigens in human immunodeficiency virus 1-infected patients before and after HAART: comparison with classical soluble HLA-A, - B, -C antigens and potential role in immunereconstitution. Clin Immunol. 2009;133:238-44.

41. Shi WW, Lin AF, Xu DP, Bao WG, Zhang JG, Chen SY, et al. Plasma soluble human leukocyte antigen-G expression is a potential clinical biomarker in patients with hepatitis B virus infection. Hum Immunol. 2011;72:1068-73.

42. Celsi F, Catamo E, Kleiner G, Tricarico PM, Vuch J, Crovella S. HLA-G/C, miRNAs, and their role in HIV infection and replication. Biomed Res Int 2013;2013:693643. doi:10.1155/2013/693643.

43. Naji A, Menier C, Morandi F, Agaugue S, Maki G, Ferretti E, et al. Binding of HLA-G to ITIM-bearing Ig-like transcript 2 receptor suppresses B cell responses. J Immunol. 2014;192:1536-46.

44. Cohen S, MCGregor IA, Carrington S. Gamma-globulin and acquired immunity to human malaria. Nature. 1961;192:733-7.

45. Bouharoun-Tayoun H, Attanath P, Sabchareon A, Chongsuphajaisiddhi T, Druilhe P. Antibodies that protect humans against Plasmodium falciparum blood stages do not on their own inhibit parasite growth and invasion in vitro, but act in cooperation with monocytes. J Exp Med. 1990;172:1633-41.

46. Sabchareon A, Burnouf T, Ouattara D, Attanath P, Bouharoun-Tayoun $\mathrm{H}$, Chantavanich $\mathrm{P}$, et al. Parasitologic and clinical human response to immunoglobulin administration in falciparum malaria. Am J Trop Med Hyg. 1991;45:297-308.

47. Simon MC, Keith B. The role of oxygen availability in embryonic development and stem cell function. Nat Rev Mol Cell Biol. 2008;9:285-96. 
48. Pouyssegur J, Dayan F, Mazure NM. Hypoxia signalling in cancer and approaches to enforce tumour regression. Nature. 2006;441:437-43.

49. Bourguignon M, Yaghi L, Flajollet S, Radanne-Krawice I, Rouas-Freiss $\mathrm{N}$, Lugrin D, et al. Increased soluble human leukocyte antigen-G levels in peripheral blood from climbers on Mount Everest. Hum Immunol. 2010;71:1105-8.

50. Miller LH, Ackerman HC, Su XZ, Wellems TE. Malaria biology and disease pathogenesis: insights for new treatments. Nat Med. 2013;19:156-67.

51. Yeo TW, Lampah DA, Kenangalem E, Tjitra E, Weinberg JB, Granger DL, et al. Decreased endothelial nitric oxide bioavailability, impaired microvascular function, and increased tissue oxygen consumption in children with falciparum malaria. J Infect Dis. 2014;210:1627-32.

52. Kramer MS. Determinants of low birth weight: methodological assessment and meta-analysis. Bull World Health Organ. 1987;65:663-737.

53. McCormick MC. The contribution of low birth weight to infant mortality and childhood morbidity. N Engl J Med. 1985;312:82-90.

54. Ntuli ST, Malangu N, Alberts M. Causes of deaths in children under-five years old at a tertiary hospital in Limpopo province of South Africa. Glob J Health Sci. 2013;5:95-100.

55. Lawn JE, Cousens S, Zupan J, Steering LNS. Neonatal survival 1-4 million neonatal deaths: When? Where? Why? Lancet. 2005;365:891-900.

56. Warner CM, Comiskey M, Clisham PR, Brenner CA. Soluble HLA-G (sHLAG) a predictor of IVF outcome? J Assist Reprod Gen. 2004;21:315-6.

57. Ciprandi G, DeAmici M. Soluble HLA-G serum levels depend on allergy type and IgE levels. Allergy Rhinol (Providence). 2014;5:9-11.
58. Seliger B. The non-classical antigens of HLA-G and HLA-E as diagnostic and prognostic biomarkers and as therapeutic targets in transplantation and tumors. Clin Transpl. 2013;465-72.

59. Zeestraten EC, Reimers MS, Saadatmand S, Dekker JW, Liefers GJ, van den Elsen PJ, et al. Combined analysis of HLA class I, HLA-E and HLA-G predicts prognosis in colon cancer patients. Br J Cancer. 2014;110:459-68.

60. Proust-Lima C, Sene M, Taylor JM, Jacqmin-Gadda H. Joint latent class models for longitudinal and time-to-event data: a review. Stat Methods Med Res. 2014;23:74-90.

61. Nagin DS, Odgers CL. Group-based trajectory modeling in clinical research. Annu Rev Clin Psychol. 2010;6:109-38.

62. Nagin DS, Tremblay RE. Developmental trajectory groups: fact or a useful statistical fiction? Criminology. 2005;43:873-904.

63. Storr CL, Zhou HL, Liang KY, Anthony JC. Empirically derived latent classes of tobacco dependence syndromes observed in recent-onset tobacco smokers: epidemiological evidence from a national probability sample survey. Nicotine Tob Res. 2004;6:533-45.

64. Nylund KL, Asparoutiov T, Muthen BO. Deciding on the number of classes in latent class analysis and growth mixture modeling: a Monte Carlo simulation study. Struct Equ Model. 2007;14:535-69.

65. Gineau L, Luisi P, Castelli EC, Milet J, Courtin D, Cagnin N, et al. Balancing immunity and tolerance: genetic footprint of natural selection in the transcriptional regulatory region of HLA-G. Genes Immun. 2014;16:57-60.

\section{Submit your next manuscript to BioMed Central and we will help you at every step:}

- We accept pre-submission inquiries

- Our selector tool helps you to find the most relevant journal

- We provide round the clock customer support

- Convenient online submission

- Thorough peer review

- Inclusion in PubMed and all major indexing services

- Maximum visibility for your research

Submit your manuscript at www.biomedcentral.com/submit
() Biomed Central 